I would beg to rent the Fth and 11 th rules in wty work, "Aids during Labour," for the guidance of those who desire to use it in midwifery:- " Eet the countenance auk voice be your guides for the continuance of the inhalation. If the woman cry ercifervusly and the features evince suffering, continue the inhalation a little longer. Commonly, about four or six inspi. rations suffice." p. 86. "Give some stimulant from time to time, as may judged admissible especially if vertigo or weakness be complained of, even if the pulse do not alter in its charaeten." p. 87.

The small size of the inhaler and its thorough efficiency will, I believe, lead to its general adoption.

I am, Sir, your most obedient servant,

Baykinn-terrace, Camden Town, J. R. Pretty, M. D.

February, 1857.

\section{MEDICAL REGISTRARS.}

To the Editor of The LANCET.

STr, - I think you would be doing the medical profession a service if you would call the attention of the proper authorities to the impropriety of appointing a medical practitioner to the office of registrar of births and deaths. I consider it most unfair to other practitioners in the same place and locality, and what guarantee is there of their giving a true statement of the cause of death in all cases of their own patients?

I am, Sir, your obedient servant,

Kineton, Feb. 1857. JoHN EDmunds, Surgeon, \&c.

\section{UNQUALIFIED PRACTITIONERS AND REGIS. TRATION OF DEATHS. \\ To the Editor of THE LANCET.}

SrR,--I have on several occasions observed letters in your journal, calling the attention of the Apothecaries' Society to the number of druggists in this town who officiate as general practitioners, visiting, dispensing, and giving certificates of death. That such conduct is detrimental to the public health may be gathered from the following facts:-

On Wednesday, the 11th of February, a meeting of the medical gentlemen of this place was convened by the mayor, who called their attention to a letter he had received from the Registrar-General, stating that for a period of ten years past the annual mortality of Coventry had exceeded the average of other manufacturing towns by thirty per cent. The gentlemen present were invited to discuss the matter, but were unable to assign any certain cause for the same, but several expressed an opinion that the increase might be occasioned by the malpractice of uneducated men, as they were constantly called in to see patients when in articulo mortis, who up to that period had been attended by druggists. This will also account for such causes of death as the following, which are enumerated in the registers-viz., "crick," "death-struck," "infection," "frogs" - whether applied externally, or taken inwardly, does not appear-" stoppage," \&c. \&c., all of which must be of vast assistance to the Registrar-General when making up his statistical nosology.

To the list of mortality may be added two cases of poisoning which have occurred in the neighbourhood within six months, in both of which the poison was detected by analysis postmortem, bat nevertheless the prisoners were acquitted. Inquests are not deemed so frequently necessary as in many parts of England, and when so, medical evidence is often dispensed with, as the following cases will testify:-

A man mamed Pearson, after breakfast became suddenly ill, and died before medical attendance could be obtained. $\mathrm{He}$ had for years previously complained of pains in his chest, and the coroner was satisfied that he died of heart-disease.

A child labouring under hydrocephalus was scalded by an idiot, and died in ten days of convalsions. An inquest was held, and a verdict returned without medical evidence. The idiot also diel, but he was not considered worthy of an inquest.

A woman amed Davis, having spent a Sunday with her friends, soon after reaching home was taken ill with pain in the chest, and died almost instantly. No inquest was thought necessary, as it was evident to all that she was " death-struck." This woman belonged to a brarial society.

A child was crushed by a cart, and died of pneumonia in three days. An inquest was held, but an medical evidence required.

I have tine honour to remain, Sir, Tour most obedient servant

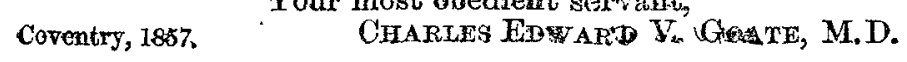

\section{POOR-LAW MEDICAL REFORM.}

M HWTNG OF THE DELEGATES OF THE LONDON SCHOOLS OF MEDICINE.

Aт a meeting of delegates from each of the London schools of medicine, it was decided that an aggregate meeting of students was very desirable. At the next meeting of this general committee, it was decided that this meeting should take place before the end of the present session, (within a fortnight, if possible.) A sub-committee was appointed to select a chairman, a suitable place for the meeting, to draw up resolutions, to get funds, \&c., \&c. The committee met again at University College on Tuesday last, to hear the report of the sub-committee. Mr. Layard, M.P., had consented to preside. Since this meeting, the day of meeting has been fixed for Thursday next, at St. Martin's Hall, Long-acre, at half-past seven P.M. The sub-committee have been in communication with the various provincial schools, and these have come forward in the most generous manner in answer to the appeal. Many have already promised to send delegates, and a few have named their representatives. The committee have solicited subscriptions for the general fund, and have a good amount in hand The great tinanimity existing amongst the members of the committee of delegates is very gratifying, and angurs well for the cause, and the same feelings doubtless exist amongst the students themselves.

The committee acknowledged the manly manner in which many of the provincial schools have responded to their call, and made an especial reference to that of St. Steven's Hospital Dublin.

\section{MEETING OF THE STUDENTS OF WESTMINSTER HOSPITAL.}

A MeEting of the students of this hospital took place on the 16 th vilt., when the following resolutions were put to the meeting, and unanimously agreed to-Mr. Harris being in the chair :

Proposed by Mr. Lake, seconded by Mr. Tebay-1. "That this meeting is of opinion that the present rate of payment to union medical officers is utterly inadequate compensation for the numerous and important duties they are called upon to perform."

Proposed by Mr. Beadles, seconded by Mr. Hill.-2. "That this meeting cousiders that the Poor-law guardians ought not to have the sole power of determining the rate of payment of the medical officers."

Proposed by Mr. Ford, seconded by Mr. Squire-3. "That this meeting offers its thanks to R. Griffin, Esq., for his exertions on behalf of Poor-law Medical Reform, and promises him its support."

Proposed by Mr. Dowell, seconded by Mr. Greenwood4. "That this meeting is of opinion that an aggregate meeting of the students of the metropolis is necessary for the furtherance of the objects of Poor-law Medical Reform."

Proposed by Mr. M'Cann and seconded by Mr. Kennard5. "That Mr. Perreau be appointed Secretary, and Mr. Drake, Treasurer, and that these gentlemen be empowered to represent the students of this hospital, in conference with delegates from the varions other metropolitan schools."

Proposed by Mr. Perrean and seconded by Mr. Drake-6. "That a shilling subscription be raised for the purpose of defraying expenses."

\section{MEETING OF THE STUDENTS OF THE BRISTOL ROYAL} INFLRMARY.

A meeting of the students of the Bristol Medical School was held at the Bristol Royal Infirmary on Friday last, February 27th, for the purpose of supporting Mr. Griffin's movement in Poor-law Medical Eeform-T. E. Clark, M.R.C.S., in the chair. The following resolutions were adopted.

Proposed by Mr. Hornfrag and seconded by Mr. Featherstone -1. "That this meeting tenders its best thanks to Mr. Griffin for his unwearied zeal and exertions in behalf of Poor-law Medical Reform."

Proposed by Mr. Willey and seconded by Mrr. Webster2. "That this meeting seeks to support Mr. Griffin's movement, considering the present system of appointing and remunerating Poor-law medical officers perfectly unjust."

Proposed by Mr. Grace and seconded by Mr. G. Ormerod3. "That this meeting earnestly urge their brother students in the United Kingdom to join in pledging themselves, that on the completion of their studies they will not accept any ap- 